\title{
A CULTURA KAINGANG E O SCRATCH NAS AULAS DE MATEMÁTICA: UMA PROPOSTA PEDAGÓGICA PARA O ENSINO FUNDAMENTAL A PARTIR DO OLHAR ETNOMATEMÁTICO
}

\author{
Agner Lopes Bitencourt, UFRGS \\ agnerlb@gmail.com - https://orcid.org/0000-0002-2968-0690 \\ Emanoel Gil Ferreira, UFRGS \\ emanoelf54@gmail.com - https://orcid.org/0000-0002-9640-3212
}

\section{Resumo}

Este artigo apresenta uma proposta pedagógica em desenvolvimento envolvendo a cultura indígena Kaingang e a programação no software Scratch. Intenciona-se aplicá-la com alunos do Ensino Fundamental na disciplina de Matemática, tendo como objetivo aprender e refletir sobre culturas que estão em interação com a cultura dos alunos. $\mathrm{O}$ Scratch servirá para simular grafismos ou outros aspectos da cultura Kaingang através da programação de animações, de forma que a matemática acadêmica faça parte deste processo. A proposta permite trabalhar a matemática como um meio para representar e conhecer culturas e conhecimentos de outras fontes não acadêmicas e estimular a criatividade dos estudantes. Por fim, espera-se que os alunos reflitam sobre os significados culturais representados na arte indígena e, com isso, possam respeitar as diferenças, pois vivem em uma sociedade com marcas da multiculturalidade. Palavraschave: Etnomatemática, Tecnologias Digitais, Cultura Indígena Kaingang.

\section{KAINGANG CULTURE AND SCRATCH IN MATHEMATICS CLASSES: A PEDAGOGICAL PROPOSAL FOR ELEMENTARY SCHOOL FROM THE ETHNOMATHEMATICAL POINT OF VIEW}

\begin{abstract}
This article presents a pedagogical proposal in development involving the indigenous Kaingang culture and programming in Scratch software. It is intended to apply it with elementary school students in the discipline of Mathematics, with the objective of learning and reflecting on other cultures that are in interaction with the students' culture. Scratch will serve to simulate graphics or other aspects of Kaingang culture through the programming animations, so that academic mathematical knowledge is part of this process. This proposal allows working with mathematics as a means to represent and learn about cultures and knowledge from other non-academic sources and stimulate students' creativity. At last, it is expected that students will reflect on the cultural meanings represented in indigenous art and, with this, can respect differences, once they live in a society with marks of multiculturalism.

Keywords: Ethnomathematics, Digital Technologies, Kaingang Indigenous Culture.
\end{abstract}

\section{Introdução}

Somos sujeitos de uma sociedade em que a informação é abundante. Nesse sentido, diferentes conceitos que haviam sido construídos no passado, baseados em uma visão eurocêntrica do mundo, estão sendo reconsiderados e caindo em desuso. Junto dessa renovação de conceitos, o ensino de Matemática tem sido alvo, cada vez mais, de pesquisas para que consiga renovar o interesse dos alunos que não se sentem motivados pelo modelo clássico de ensino, pela maneira tradicional de estudar e aprender Matemática. 
A partir dessa ideia de trazer novas formas de aprender Matemática, surge a etnomatemática de D'Ambrósio (2008), que apresenta uma perspectiva de estudar a Matemática conforme a realidade cultural dos alunos. Desse modo, acredita-se que através da etnomatemática é possível trazer conhecimentos importantes para os alunos, inclusive do ponto de vista da matemática formal, estudando culturas que não são amplamente divulgadas. Inspirados por curiosidade pessoal, a pesquisa começa investigando sobre culturas indígenas, bem como suas representações artísticas e significados. Encontram-se diversas etnias de culturas riquíssimas e, pelo fato da construção histórica do Rio Grande do Sul, optou-se por trabalhar com a cultura local, mais especificamente, a cultura dos índios Kaingang.

Concorda-se com Costa, Tenório e Tenório (2014), que afirmam que a etnomatemática indígena necessita de maior abordagem nas salas de aula, para que os alunos entendam mais sobre grupos étnicos que compõem a sociedade. A partir dessa perspectiva, decidiu-se montar uma proposta que utiliza a etnomatemática como base metodológica, aliando-se com a utilização das novas Tecnologias Digitais (TD).

A seguir, apresenta-se a visão etnomatemática de estudar a cultura de outrem sem deixar a cultura do aluno de lado, de forma que preparamos esta proposta voltada para que alunos da Educação Básica (não-indígenas) aprendam sobre a cultura Kaingang. Para isso, optou-se pelo uso do Scratch, o qual contém a possibilidade de interface entre as culturas dos alunos com a indígena. Pretende-se que os alunos nãoindígenas se utilizem dessa ferramenta para contar histórias ou ilustrar fatos que apresentam os significados da cultura Kaingang.

\section{Etnomatemática}

A etnomatemática visa entender o saber/fazer Matemática de diferentes grupos culturais. Esse programa, ao adentrar as escolas, confronta a visão curricular predominante em que se valorizam os aspectos acadêmicos das disciplinas em detrimento de outras formas de conhecer. Dessa forma, a etnomatemática busca formas de assimilar conhecimentos matemáticos de culturas diferentes, sem que isto implique um "choque com o com o saber matemático que é próprio" (D’AMBRÓSIO, 2008, p. 10) dos estudantes na sua cultura de origem.

Segundo Costa et al. (2014), o programa etnomatemática não se limita apenas à Matemática como ciência formal, mas caminha em direção ao exercício da cidadania pela compreensão, preservação e interação das diferentes culturas existentes em nosso planeta. Logo, quando se pretende "estudar Matemática" pelo olhar da etnomatemática, busca-se a compreensão de como o ser humano vem elaborando e se utilizando de sistemas matemáticos para resolver os problemas cotidianos.

A cultura indígena, por exemplo, utiliza-se da geometria tanto em seus grafismos quanto na cestaria, apresentando padrões de construção, simetrias, reflexões, translações, etc. Tais conhecimentos são aplicados exclusivamente com essa finalidade devido ao modo de viver indígena, bem como de suas necessidades diárias. Logo, conhecer os sistemas matemáticos empregados nesses processos pode auxiliar na compreensão da Matemática enquanto uma ciência humana, que foi sendo desenvolvida ao longo do tempo e pode, inclusive, auxiliar outras culturas a resolverem problemas semelhantes ou a otimizar algum processo de sua cultura (D’ABMRÓSIO, 2008).

A etnomatemática oportuniza reflexões para que se incorporem os conhecimentos científicos da sociedade atual no processo educativo dos indivíduos, ou seja, além da busca pela compreensão da cultura do outro, visa-se conhecer o desenvolvimento da própria cultura. É possível pensar na utilização das Tecnologias V. $19 \mathrm{~N}^{\mathrm{o}} 1$, julho, 2021 DOI: https://doi.org/10.22456/1679-1916.118540 RENOTE 
Digitais em sala de aula, tendo em vista que elas são marcantes na sociedade atual, a qual "comporta novas maneiras de trabalhar, de comunicar-se, de relacionar-se, de aprender, de pensar e, em suma, de viver" (COLL; MONREO, 2010, p. 2).

Conforme afirmam as ideias da etnomatemática, ao se conhecer a cultura do outro e a própria, busca-se um desenvolvimento mais pleno do ser humano. Para tanto, D’Ambrósio (2013) propõe uma dimensão da etnomatemática denominada Educacional. Essa dimensão defende a não substituição da Matemática Acadêmica por uma etnomatemática específica, tendo em vista que parte da sociedade atual foi construída com base na Matemática Acadêmica. Se um sujeito pretende compreender e atuar criticamente em sua sociedade, faz-se necessário que conheça os pilares sobre os quais foi construída. Além disso, ofertar uma formação embasada exclusivamente em outra cultura, pode não desenvolver nos indivíduos as características suficientes para uma atuação autônoma na sociedade à qual pertencem.

Outro aspecto da dimensão educacional refere-se ao olhar qualitativo, "pois permite exercer crítica e análise do mundo em que vivemos" (D’AMBRÓSIO, 2013, p. 43). A etnomatemática se enquadra numa visão holística da educação, de forma que o contexto deve se fazer presente, sendo que ele apresenta-se vinculado à manifestações culturais. Uma vez que atualmente existem formas rápidas de comunicação e trocas de informações entre culturas por meio da Internet, o autor afirma que a multiculturalidade é uma característica marcante da sociedade e, por isso, podem haver conflitos que apenas serão resolvidos através do conhecimento de si e do outro, de sua própria cultura e das que lhe são alheias. Do contrário, haverá desconhecimento, intolerância, sentimentos de superioridade e, possivelmente, violência.

A escola, nesse quesito, torna-se uma instituição com potencialidades para alterar este curso de violências e preconceitos, contudo, desde que se assuma a paz como objetivo maior da Educação. Para D’Ambrósio (2013, p. 45), a "proposta pedagógica da etnomatemática é fazer da matemática algo vivo, lidando com situações reais no tempo [agora] e no espaço [aqui]. E, através da crítica, questionar o aqui e agora". Aceita-se, assim, as mudanças que virão no futuro, em especial, o fortalecimento da multiculturalidade, da hibridização, de forma que nossas crianças de hoje precisarão lidar com essas questões, agindo e tomando decisões para si e para seu entorno, na tentativa de melhorar a qualidade de vida e de viver em paz.

\section{A cultura Kaingang}

Os Kaingang são uma tribo indígena que habita os territórios que correspondem às florestas de pinhais, nos atuais estados de São Paulo, Paraná, Santa Catarina, Rio Grande do Sul e a Província de Missiones, ao norte da Argentina. Sua população chega a 29 mil indivíduos, colocando o grupo entre os três mais populosos do Brasil. A palavra "Kaingang" é a forma como os não-índios os chamam, mas o grupo se autodenomina kanhgág, significando "gente", "pessoa", "índio" (SOUZA, 2011).

Segundo Ribeiro (2012), os diferentes mitos das tribos indígenas têm como finalidade explicar fenômenos, exprimir sentimentos, mostrar deveres e valores da tribo e ensinar a história de seu povo. A organização sócio-cosmológica da tribo Kaingang divide todos os seres, objetos e fenômenos naturais em duas metades assimétricas e complementares, que derivam de dois gêmeos ancestrais, denominados Kainrú e Kamé ${ }^{\text {, }}$ os quais foram responsáveis por ajudar o povo Kaingang a resolver as rixas internas que

1 Existem diferentes grafias para os nomes dos gêmeos ancestrais, as quais podem ser encontradas em Sufiatti, Bernardi e Duarte (2013). 
havia na tribo. Essa divisão dos gêmeos ancestrais permite a identificação de características relacionadas a cada um (SILVA, 2001), como ilustra o quadro 1.

A dualidade cosmológica que permeia a sociedade Kaingang é representada através da arte e de seus grafismos aplicados nos próprios corpos ou nos materiais e utensílios indígenas. Esses grafismos possuem a finalidade de mostrar aos demais a ancestralidade de uma pessoa Kaingang, isto é, de qual irmão gêmeo é descendente. Segundo Ribeiro (2012), o grafismo indígena é uma parte importante no processo cultural e está presente nas pinturas corporais, não somente como um acréscimo à beleza estética, mas também de significados sociológicos e religiosos.

Quadro 1 - Características da dualidade cosmológica de Kamé e Kainrú.

\begin{tabular}{|l|l|}
\hline \multicolumn{1}{|c|}{ Kainrú } & \multicolumn{1}{c|}{ Kamé } \\
\hline Gêmeo ancestral denominado Kainrú; & Gêmeo ancestral denominado Kamé; \\
\hline Lua, um ex sol; & Sol, símbolo de força e poder; \\
\hline Noite; & Dia; \\
\hline Corpo fino, peludo, pés pequenos; & Corpo grosso, pés grandes; \\
\hline Frágil, menos forte; & Mais forte; \\
\hline Feminino; & Masculino; \\
\hline Ligeiro em movimentos e resoluções; & Vagaroso em movimentos e resoluções; \\
\hline Menos persistente; & Persistente; \\
\hline Pintura corporal redonda, "fechada"; & Pintura corporal em faixas, linhas, “aberta”; \\
\hline$(\ldots)$ & $(\ldots)$ \\
\hline
\end{tabular}

Fonte: (SILVA, 2001, p. 101).

As formas linhas retas ou curvas, formando contornos abertos são elementos relacionados a Kamé, ou seja, representam índios que são descendentes dessa linhagem. Já os contornos fechados circulares são relacionados a Kainrú, mostrando os índios que são seus descendentes, como pode ser visto na figura 1.

Segundo o mito Kaingang, os gêmeos Kainrú e Kamé se casaram com moças Kaingang e tiveram filhos com elas. Devido a interferência dos gêmeos ancestrais no surgimento do povo, a sociedade Kaingang é exogâmica e patrilinear, ou seja, os filhos são pertencentes à metade cosmológica paterna, recebendo as mesmas marcas de seu pai e não da sua mãe. Além do mais, um casal Kaingang deve ser formado por uma parte descendente de Kainrú e outra descendente de Kamé, de modo que um índio seja composto pelas duas metades cosmológicas.

Com o passar do tempo, os Kaingang tiveram contato com outras tribos e seus membros se casaram entre si. Desses casamentos surgiram mais duas etnias: os Wonhétky, descendentes da linhagem Kamé com outras etnias indígenas, aos quais fora designado o grafismo das linhas curvas, e os Votor, descendentes da linhagem Kainrú com outras etnias indígenas, aos quais fora designado o grafismo dos círculos.

Figura 1 - Grafismos Corporais Kaingang. 


CINTED-UFRGS Revista Novas Tecnologias na Educação

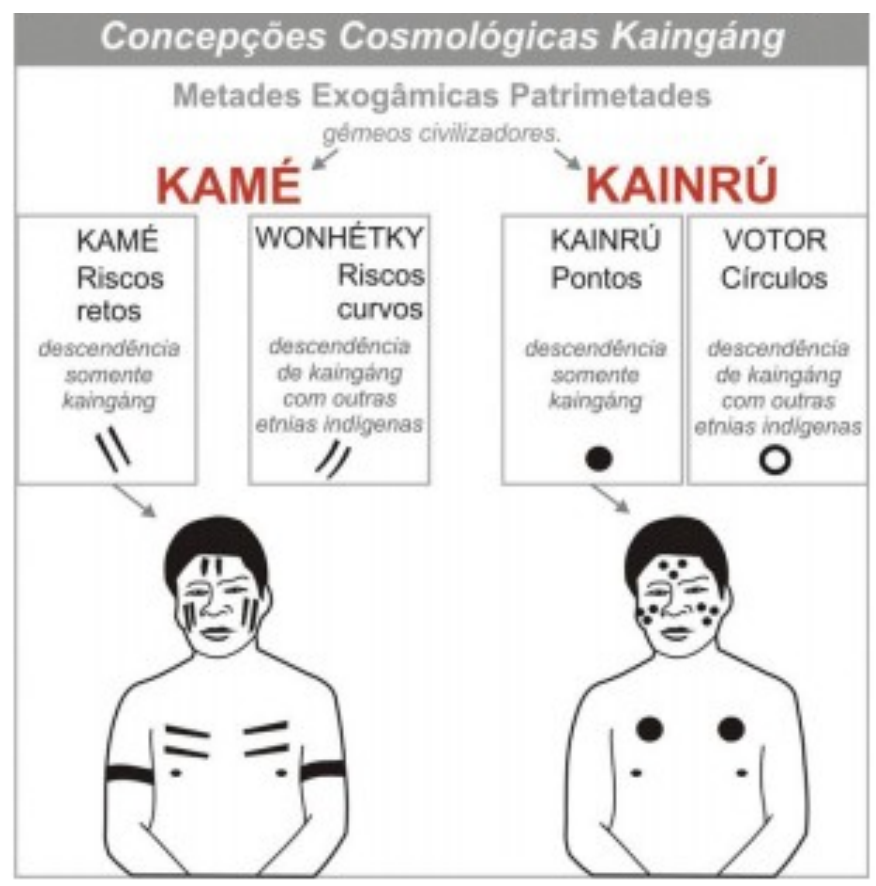

Fonte: (SUFIATTI et al., 2007, p. 71).

Os grafismos também são utilizados na arte, como garrafas, cestas, arcos, flechas, tapeçarias, dentre outras, eles representam no material a linhagem de seu artesão. Assim, um cesto feito por alguém da linhagem Kamé, terá em seu trançado linhas e setas junto de outros símbolos, enquanto que o cesto feito por um indivíduo da linhagem Kainrú, terá formas fechadas, puntiformes (vale ressaltar que, por motivos físicos, geralmente os símbolos Kainrú na cestaria acabam tendo acabamentos mais quadrados do que redondos). Outros exemplos são os arcos e flechas, os quais apresentam anéis pintados ou linhas desenhadas em torno da madeira, além de existirem cestas matrimoniais ou garrafas ritualísticas que juntam os grafismos de ambas as linhagens. A figura 2 apresenta alguns símbolos associados à linhagem Kamé e Kainrú.

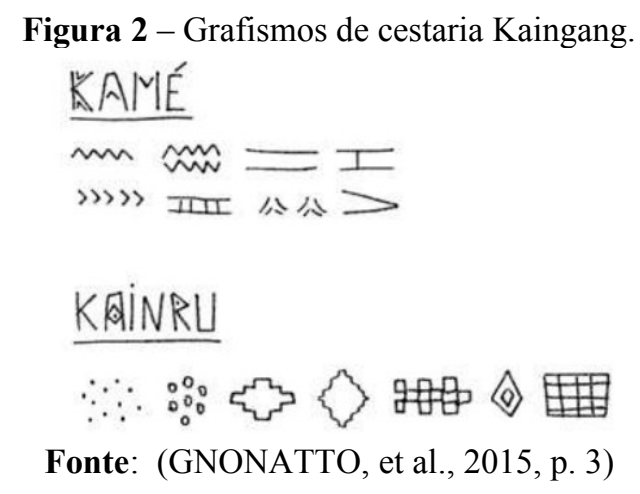

Segundo Ribeiro (2012), a arte indígena sempre foi pautada no sujeito, de maneira que a pintura corporal toma diversos significados para cada tribo, no sentido de diferenciar os seus integrantes dentro da sociedade e também no de evocar significados em seus rituais. Os Kaingang apresentam em sua arte não apenas a visão de significado ritualístico, mas também a complexidade de sua história e a maneira de enxergar a tribo e a organização dela através de sua vivência enquanto povo. 


\section{As Tecnologias Digitais e as potencialidades do Scratch}

Segundo Coll e Monereo (2010, p. 4), vive-se em uma sociedade marcada pela informação e pelas modificações econômicas, políticas e sociais causadas pelo aumento do acesso às Tecnologias Digitais (TD). Há uma "facilidade para comunicar-se e trocar informações, junto com a enorme redução de custos", fazendo com que países invistam em sua utilização. No campo da Educação, as TD promoveram modificações nos formatos educativos ao longo do tempo, que perpassam desde a fala, a mímica, com modalidades educacionais de repetição e imitação, até a fase atual, com a presença de computadores e Internet, propiciando modalidades como o ensino à distância ou como e-learning. Por outro lado, o número de indivíduos que as utilizam vem aumentando, em uma busca de melhorar sua qualidade de vida.

As estatísticas apresentadas pela Pesquisa Nacional por Amostra de Domicílios Contínua (PNADC, 2018) apontam que o acesso dos brasileiros às TD tem aumentado nos últimos anos. A pesquisa apresentou variações quanto ao tipo de tecnologia utilizada, assim como a possibilidade de acessar a internet. Constatou-se que 93,2\% dos domicílios brasileiros possuem telefones móveis, 41,7\%, microcomputadores, 96,4\%, televisores e 12, 5\%, tablets. Em relação ao acesso à internet, constatou-se que $79,1 \%$ dos brasileiros acessam-na através dos equipamentos citados, ficando o telefone móvel em primeiro lugar, seguido dos microcomputadores.

Contudo, apesar da presença significativa das TD nas mãos dos brasileiros, as escolas ainda carecem desses recursos, assim como de profissionais com formação crítica adequada para extrair deles potencialidades educacionais. Mas por que usar TD em sala de aula? Maltempi e Mendes (2016) argumentam que as tecnologias, independentemente de serem digitais ou analógicas, podem ser compreendidas como extensões de faculdades humanas (físicas ou psíquicas), alterando a maneira como as pessoas pensam, agem e compreendem o mundo. E, talvez por isso, as pessoas tenham interesse em utilizá-las cotidianamente, seja na forma de ferramenta, seja para resolverem problemas, seja para acessarem informações de que necessitam.

Existem vantagens de utilizar TD com fins pedagógicos, tais como "gerar múltiplas representações do conhecimento (estáticas e dinâmicas); oferecer interatividade com o conteúdo e a possibilidade de colaboração com outros aprendizes ou especialistas e realizar cálculos matemáticos com grande eficiência" (MALTEMPI; MENDES, 2016, p. 89). Segundo Borba et al. (2014), o desenvolvimento tecnológico possibilita ao usuário realizar investigações matemáticas através de softwares educacionais, pois potencializam um ambiente marcado "pela natureza dinâmica, visual e experimental" (p. 227).

O software Scratch proporciona ao seu usuário lidar com programação, a qual possibilita criar tecnologia e não simplesmente manuseá-la. Através dessa forma de uso, os alunos não lidam apenas com o certo e o errado, mas refletem sobre suas decisões a partir da simulação das ações executadas pelo computador. Logo, também há contribuições para o "desenvolvimento de conceitos e a resolução de problemas" (BRAND, 2019, p. 34), pois os alunos precisam criar estratégias, testá-las e validá-las para dar forma ao seu projeto.

Consequentemente, pensar o uso das TD na Educação Matemática significa repensar o modo tradicional no qual, geralmente, é ministrada essa ciência, uma vez que abrem-se espaços para discussões conceituais dos conteúdos e menos procedurais. Portanto, no viés da etnomatemática, cabe proporcionar uma discussão que respeite "a cultura, os saberes, e as práticas de cada grupo" (COSTA et al., 2014, p. 1099). Ademais, as TD podem reconfigurar os papéis dos envolvidos no processo educativo, V. $19 \mathrm{~N}^{\mathrm{o}} 1$, julho, 2021 DOI: https://doi.org/10.22456/1679-1916.118540 RENOTE 
pois parecem atribuir novas atuações aos alunos, como as de analisar informações para produzir e sistematizar conhecimentos e aos professores, enquanto coparticipantes da aprendizagem de seus estudantes (MALTEMPI; MENDES, 2016).

\subsection{O Scratch}

O Scratch é um software livre que foi desenvolvido pelo Massachusetts Institute of Technology (MIT) de Boston com a Portugal Telecom, produzido inicialmente para crianças e jovens entre 8 e 16 anos. Porém, devido ao seu potencial educacional ele é utilizado por pessoas de todas as idades, como um espaço de criatividade que utiliza uma linguagem de programação baseada em blocos encaixáveis entre si. Os comandos programados através dessa linguagem comandam um ou mais atores que podem executar diversas ações, como andar e falar, tanto através de balões de texto, como por áudios, dentre outras opções de comandos.

Sua interface apresenta basicamente três áreas: comandos, programação e palco. A primeira área oferta um conjunto de comandos que fica à disposição para serem arrastados para a segunda área, na qual são feitas as conexões entre os blocos, montando a programação a ser executada. A terceira área é uma janela de visualização da programação realizada. Dessa forma, é possível montar um bloco de comandos e prévisualizar sua execução. A figura 3, apresenta a tela inicial do Scratch.

O site do Scratch conta com tutoriais e projetos compartilhados pela comunidade de usuários, dentre os quais é possível olhar a programação desenvolvida pelo seu criador, uma wiki e fóruns em que são tratados os mais diversos conteúdos/temáticas/assuntos envolvendo o software. Vale ressaltar que o Scratch pode ser acessado por computadores através de download do programa ou pelo navegador de internet, nesse último caso ele também pode ser acessado por dispositivos móveis que possuam a funcionalidade "versão para computador".

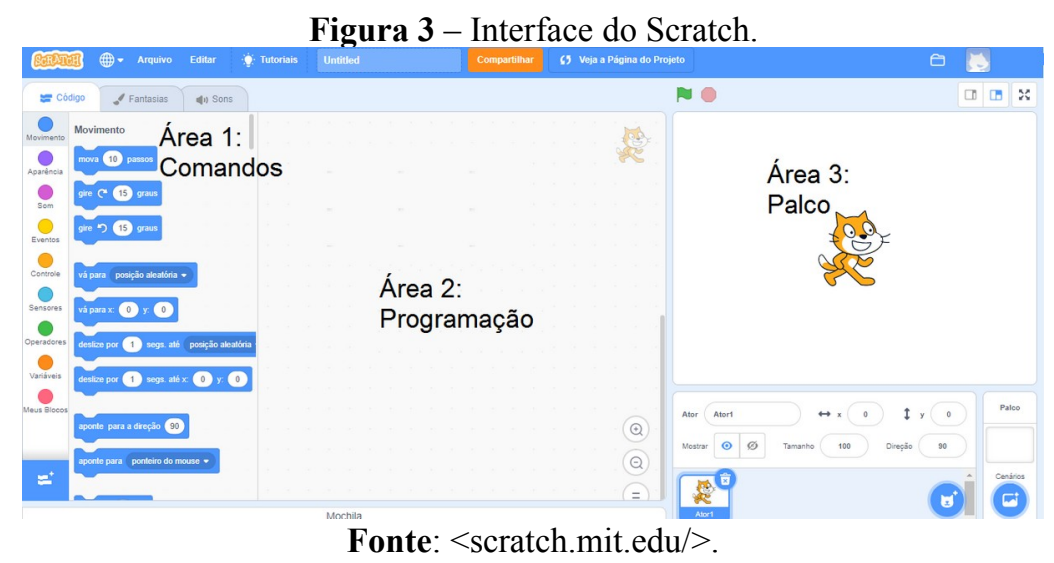

O Scratch como tecnologia educacional, possibilita a elaboração de representações do tema em estudo de forma criativa. Sua linguagem de programação requer planejamento das ações a serem executadas pelos personagens. Ao mesmo tempo, ele proporciona aprendizagem de conteúdos matemáticos e desenvolvimento de habilidades para lidar e interpretar as mídias digitais (Sápiras et al., 2015).

Assim, é possível propor aulas em que a Matemática se torna ferramenta de expressão, encorajando os alunos a serem criativos e auxiliando-os a exporem suas ideias e interpretações. Em aulas baseadas nessa proposta, os conhecimentos matemáticos fazem parte de um criar e brincar que proporciona aos alunos uma visão 
"divertida" da Matemática, que difere da visão proporcionada por "um currículo cartesiano estruturado previamente à prática educativa” (D’AMBRÓSIO, 2012, p. 81).

\section{Uma possibilidade de proposta pedagógica}

A proposta pedagógica pode ser desenvolvida com alunos da Educação Básica do Ensino Fundamental, estando em consonância com a Lei n ${ }^{\circ} 11.645$ de 2008, a qual inclui a obrigatoriedade da temática "História e Cultura Afro-Brasileira e Indígena" na formação da sociedade nacional. Tendo como objetivo refletir sobre os conhecimentos matemáticos dos povos indígenas Kaingang e suas aplicações. Para explorar esses conhecimentos, será utilizado o programa Scratch, em que é possível construir animações ou jogos que contenham elementos dos conhecimentos matemáticos indígenas, através do uso da "lógica, matemática e computação, estimulando o raciocínio sistemático e o trabalho colaborativo" (COSTA et al., 2014, p. 1111).

Contudo, para que os alunos tenham acesso à cultura indígena Kaingang é necessário que exista uma introdução, a qual pode ser feita de diferentes maneiras, como por exemplo, utilizar a contação ou leitura de histórias, vídeos ou documentários, visitas presenciais às comunidades indígenas, palestras com pesquisadores da área ou com indígenas nativos, dentre outras opções. Nesta proposta, escolheu-se vídeos curtos disponíveis na Internet ${ }^{2}$ para que os alunos possam acessar, assistir e escolher algum tema da cultura Kaingang para representar no Scratch.

Uma vez que os alunos tenham sido apresentados à cultura Kaingang, esses serão convidados a criarem uma apresentação que remonte alguma característica que mais lhe chamou a atenção. Inicia-se, assim, o processo de relacionar a programação, a Matemática e a lógica com a cultura indígena, sem deixar de lado os significados culturais dos elementos ilustrados no Scratch. A figura 4, exemplifica a elaboração de uma animação que apresenta o significado de um grafismo corporal Kaingang.

Ao analisar o processo de construção da animação, é possível perceber a utilização de conceitos matemáticos como plano cartesiano, unidades de medidas de tempo, porcentagem, números inteiros e números racionais na forma decimal. $\mathrm{Na}$ representação dos retângulos apresentados no palco, fica implícito o conceito de ângulo reto através da programação utilizada, a qual está baseada na perpendicularidade dos eixos do plano cartesiano.

A movimentação do sprite no palco pode seguir os blocos que relacionam a localização de pontos no plano cartesiano. Assim, os conceitos de coordenadas dados pelo eixo das abscissas e das ordenadas, nos quatro quadrantes são conceitos que permitem ilustrar o processo de pintura com o pincel. No caso de alguns movimentos, optou-se por adicionar valores à posição $\mathrm{x}$ ou $\mathrm{y}$, a fim de representar um deslocamento na horizontal ou na vertical, possibilitando trabalhar com operações de números inteiros, tais como adição e multiplicação.

Para representar os textos, utilizam-se os blocos específicos para fala, indicandose o tempo em segundos em que os dizeres devem permanecer na tela para visualização. Esses valores podem ser fracionados em unidades menores que 1 segundo, de acordo com os objetivos do programador. Especificamente, neste projeto, houve um deslizamento por 1,5 segundos para sincronizar com a redução no tamanho do sprite. A redução foi construída utilizando-se blocos de porcentagem, os quais aumentam ou reduzem o tamanho da fantasial.

2 Especificamente para nossa proposta, preparamos uma playlist com vídeos curtos apresentando aspectos da cultura Kaingang. Os vídeos podem ser acessados pelo link: <https://youtube.com/playlist? list=PL4wOnN5oQI-ay45jGJrRH-nbDDZ3TpnC8>. 


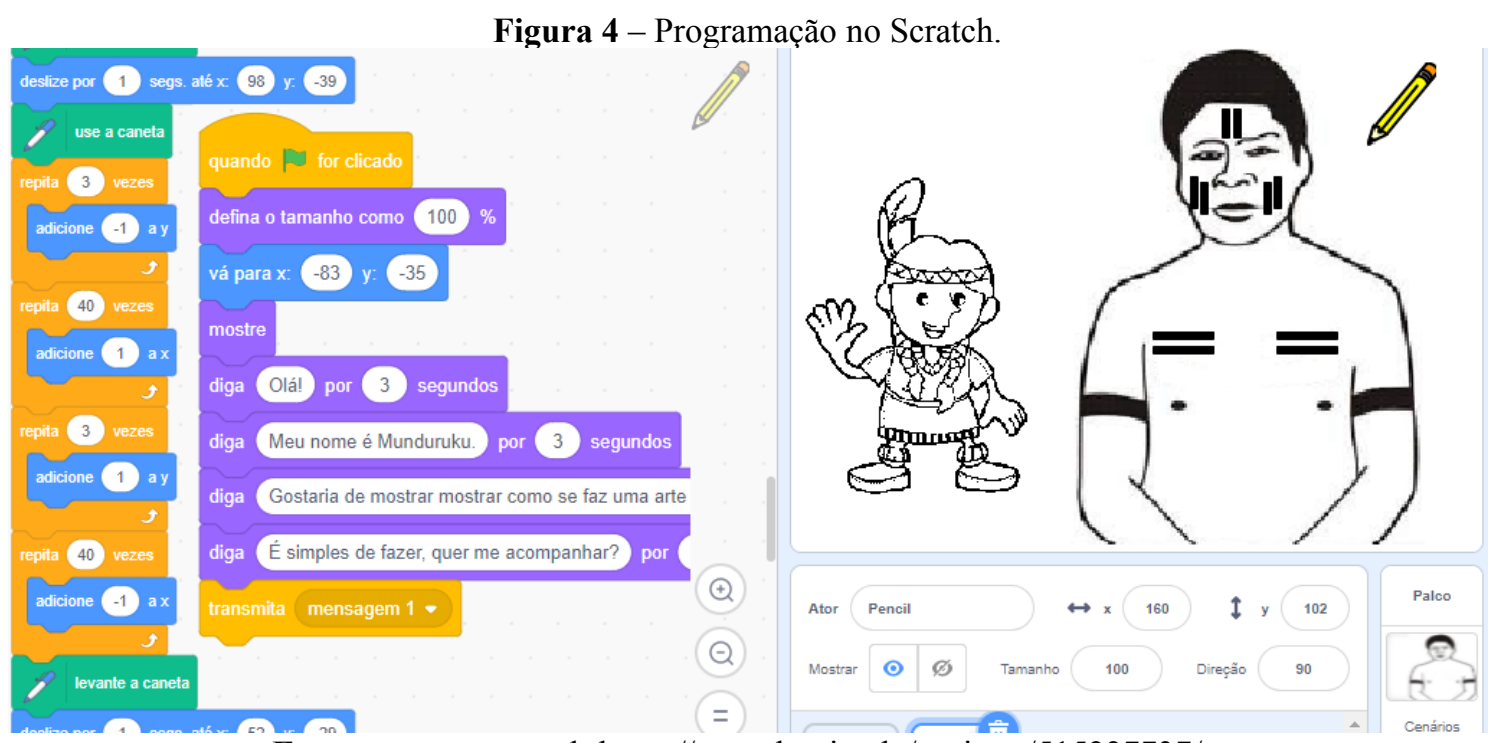

Fonte: acervo pessoal<https://scratch.mit.edu/projects/515227737/>.

A partir da janela de visualização do "palco", é possível ilustrar o grafismo corporal Kaingang através de formas geométricas em uma tentativa de imitar o movimento do pincel sobre o corpo. Não há uma técnica específica de pintura, mas caso houvesse, seria possível representá-la construindo uma programação que respeitasse sua ordem de execução. Assim, não se faz Matemática por ela mesma, pelo contrário, busca-se aliá-la à programação para se obter uma animação que representa os significados dos grafismos na cultura Kaingang.

Acreditamos que o Scratch tenha o potencial de ser a interface que une a Matemática da cultura dos alunos com os sistemas matemáticos de outras culturas. Neesta proposta pedagógica, é possível utilizar blocos referentes a ângulos ou pontos no plano cartesiano para formar um comando que representa as formas geométricas utilizadas pelos indígenas Kaingang. Esse é um modo de conhecer os significados culturais vinculados a essas representações, os quais podem ser considerados pelos alunos durante suas construções na busca de um entendimento maior da atividade, ou seja, tudo aquilo que ela pode representar para além do conhecimento matemático.

\section{Considerações finais}

A etnomatemática convida educandos e docentes a encarar a Matemática como fruto da ação humana contextualizada em diferentes tempos e locais, assim como a valorizar os diferentes saberes, evitando o caminho da superioridade de uma cultura à outra, na tentativa de construir uma sociedade baseada no respeito e na harmonia.

A cultura Kaingang é uma dentre as culturas indígenas brasileiras. Convidar os alunos das escolas regulares a conhecerem-na, pode ajudá-los a conhecerem a história e o presente de seu país, além de promover espaços para reflexão sobre as diferenças e as similaridades entre as culturas com as quais se relacionam enquanto cidadãos brasileiros.

As tecnologias digitais estão presentes na sociedade em que a maioria dos alunos das escolas regulares vivem e podem ser utilizadas para fins pedagógicos nas aulas de Matemática. No caso do Scratch, ele pode oportunizar aos estudantes a interação com o conhecimento matemático, com a lógica e com a programação para que se construam objetos digitais de forma criativa. Além de envolver outras formas de conhecimento, como no caso daqueles advindos da cultura Kaingang. 
A proposta apresentada visou a aproximação entre a cultura do aluno com a cultura Kaingang através da Matemática. Assim, a animação produzida se utilizou de conhecimentos acadêmicos para representar o sistema etno desenvolvido pelo povo indígena na esperança de que os estudantes conheçam e respeitem as diferentes formas de saberes/fazeres existentes em lugares próximos aos seus.

\section{Referências}

BORBA, M. C.; SCUCUGLIA, R.; GADANIDIS, G. Fases das Tecnologias Digitais em Educação Matemática: Sala de aula e internet em movimento. $1^{\mathrm{a}}$. ed. Belo Horizonte: Autêntica, 2014. v. 1. (E-book) Edição Kindle.

BRASIL. Congresso. Senado. Lei $\mathbf{n}^{0}$ 11.645, de 2008. Coleção de Leis da República Federativa do Brasil, Brasília, DF: Ministério da Educação e Cultura, março/abr. 2008.

BRANDT, N. PROGRAMAÇÃO NOS ANOS INICIAIS: uma contribuição para a aprendizagem da matemática. 2019. 128 fls. (Mestrado em Educação Matemática) Instituto de Matemática e Estatística, Universidade Federal do Rio Grande do Sul, 2019. COLL, C.; MONEREO, C. Psicologia da Educação Virtual: aprender e ensinar com as tecnologias da informação e da comunicação", Editora Artmed, 2010.

COSTA, B. J. F.; TENÓRIO, T.; TENÓRIO, A. A Educação Matemática no Contexto da Etnomatemática Indígena Xavante: um jogo de probabilidade condicional. Bolema, Rio Claro/SP, v. 28, n. 50, p. 1095-1116, dez. 2014.

D'AMBRÓSIO, U. Etnomatemática. Elo entre as tradições e a modernidade. Autêntica Editora, 2013. Edição do Kindle.

Educação Matemática da Teoria à Prática. 23 ed. Campinas, SP: Papirus, 2012.

O Programa Etnomatemática: uma síntese. Acta Scientiae, Canoas/RS, v.10, n.1, p. 7-16, jan.-jun. 2008.

GNOATTO, L.S.; LIMA, T.D.S.; FRANÇA, M.S. Coleção de Estampas Kaingang da Marca Curiô. Universidade Tecnológica Federal do Paraná - UTFPR, 2015. Disponível em: < https://utfprfazpesquisaemdesign.wordpress.com/2016/11/01/colecao-deestampas-kaingang-da-marca-curio/> . Acesso em: 26 abr 2021.

IBGE. Diretoria de Pesquisas. Coordenação de trabalho e rendimento. Pesquisa Nacional por Amostra de Domicílios Contínua, 2018.

MALTEMPI, M. V.; MENDES, R.O. Tecnologias Digitais na Sala de Aula: Por que não?. In: ticEDUCA 2016, 2016, Lisboa. Atas do IV Congresso Internacional TIC na Educação 2016: Tecnologias digitais e a Escola do Futuro. Lisboa: Instituto de Educação da Universidade de Lisboa. v. 1, p. 86-96, 2016.

RIBEIRO, M. M. Grafismo indígena. 2012. 60 f., il. Monografia (Licenciatura em Artes Visuais) Universidade de Brasília, Brasília, 2012.

SILVA, S. B. Etnoarqueologia dos grafismos Kaingang: um modelo para a compreensão das sociedades Proto-Jê meridionais. 2001. 367 fls. (Doutorado em Arqueologia) Faculdade de Filosofia, Letras e Ciências Humanas, Universidade de São Paulo, 2001.

SOUZA, C. E. VËNHNÏKRÉN um estudo sobre a matemática kaingang. 2011. 99 fls. (Mestrado em Educação) - Faculdade de Educação, Universidade Federal do Rio Grande do Sul, 2011.

SUFIATTI, T.; BERNARDI, L. S.; DUARTE, C.G. Cestaria e a história de vida dos artesãos indígenas da Terra Indígena Xapecó. Revista Latinoamericana de Etnomatemática, v. 6, n.1, p.67-98, mar. 2013. 